may be nervous about such openness, but the benefits far outweigh the risks.

The CTBTO has proved its worth in recent years. It detected North Korean nuclear tests in 2006 and 2009, and has captured detailed seismic data on major earthquakes, including the 2004 SumatraAndaman event that sparked a devastating tsunami.

This spring, the organization's 80 radioisotope-monitoring stations offered the clearest global picture of low-level fallout released from the Fukushima plant. Government-accredited scientific institutions were given access to provide politicians with valuable information about how the radiation was spreading and whether it posed a national threat. But most were told not to talk about the results in public, or to share the data with others in academia. The reason was diplomatic: governments such as the United States did not want to embarrass the Japanese, nor pre-empt their announcements about events unfolding at Fukushima Daiichi.

More generally, governments worry that radioisotope data are too sensitive to share. Politicians fear that, should a nuclear test occur, full access to incriminating data could somehow allow the offending nation to contest charges of weapons testing. Or perhaps that others could glean sensitive nuclear secrets from the isotopes in the atmosphere.

These fuzzy fears must be weighed against the impact of the information vacuum that followed Fukushima. Scientists everywhere were asked to give assessments, yet few had access to data that would allow them to do so. Providing open access to the CTBTO's network would have given experts the information they needed to make important statements about Japan's reactors and the threats these posed to Tokyo and beyond. The data would also have lent credibility to the Japanese government's own statements on radiation levels in the region.

Moreover, such data are scientifically useful in their own right. Atmospheric scientists use radioisotopes widely and the CTBTO network is gathering a unique data set that could be used to improve climate models or to refine meteorological studies. Scientists with access to the data might also find some new use for them. Thus far, nations have paid a combined US $\$ 1$ billion for the network, and they might as well put it to good use.

The network has already taken tentative steps towards openness. Following the 2004 tsunami, member states agreed that its seismic and hydroacoustic data could be used by accredited tsunami-warning centres around the world. In the immediate aftermath of the Fukushima Daiichi accident, it was allowed to share data with the International Atomic Energy Agency.

These are positive developments, but nations should go further: the CTBTO data are valuable in times of both calm and crisis. Contrary to the concerns of some, the more people who see them, the more valuable they will become.

\section{Great ape debate}

\section{Researchers should contribute to a US analysis of the case for chimpanzee research.}

$\mathrm{T}$ he historical value of the chimpanzee as a disease model is indisputable. It was important in developing the Sabin polio vaccine; instrumental in discovering the infectious nature of the spongiform encephalopathies; and essential to both the creation of a vaccine against hepatitis B and the identification, in 1989, of the hepatitis $\mathrm{C}$ virus (HCV).

Humankind has benefited handsomely. Since the United States instituted universal childhood vaccination for hepatitis B in 1991, there has been a $98 \%$ decline in the disease in children under the age of 15 years. And with the identification of $\mathrm{HCV}$, screening of donated blood for the virus reduced the risk of transfusion-associated hepatitis in the United States from 4\% in 1989 to almost zero in 2000.

Today, chimpanzee research is still bearing fruit, especially for hepatitis $\mathrm{C}$, a disease that infects at least 170 million people globally and often results in permanent liver damage or cancer. No approved vaccine yet exists. A study published in 2002 put the annual economic costs of the disease in the United States at more than US\$750 million.

The chimpanzee is the only animal model in which human strains of $\mathrm{HCV}$ can replicate, making it especially important in work to develop a vaccine. And studies in this animal have propelled at least one hepatitis $\mathrm{C}$ vaccine into human trials. Other chimpanzee experiments are making inroads in developing better therapies for the disease. The case for chimpanzee use in some other circumstances - such as the effort to develop a vaccine against respiratory syncytial virus, which mainly affects infants and young children - is less strong, but is at least arguable.

But chimpanzee studies are under fire (see page 268). Public discomfort over the use of chimpanzees in research has reached a historic high, with the result that the United States is now the only country save Gabon in which invasive experiments are conducted. Legislation has now been introduced in the US Congress that would prohibit invasive chimpanzee research. Although the bill is unlikely to become law any time soon in a Congress distracted by wars, debt and a moribund economy, the Great Ape Protection and Cost Savings Act is nonetheless a sign of the times.

So, too, is the fact that the National Institutes of Health (NIH), facing public pressure after proposing to return nearly 200 semi-retired chimps to active research, has commissioned a study by an Institute of Medicine (IOM) committee, which convened last month. The committee's task, to culminate in a report planned for the end of the year, is to determine whether chimpanzee studies are necessary to answer current and future biomedical and behavioural research questions, or for drug and vaccine testing - and, if so, why.

The purview of the task that the NIH has set the IOM is troubling. It contains no mention of ethical aspects of the research, and the NIH has publicly stated that this omission was deliberate. Of the 12 current members of the committee, just one is a bioethicist. The agency may wish to divorce the science from the ethics, but society at large will not accept such a distinction. Nor is it intellectually defensible: a moral choice to use intelligent, emotionally complex creatures to their detriment, for the benefit of human welfare, is intimately related to what can be achieved scientifically. It would be wrong for the NIH to make any change in its support for chimpanzee research — or indeed to maintain the status quo - solely on the basis of the scientific report from the IOM.

Still, the work of the committee will provide a valuable starting point by defining the scientific case for chimpanzee research. Working from this, ethicists, the public, the animal-protection lobby, scientists and regulators could then engage in the much-needed, wider-ranging debate. An ideal convener for such a discussion would be the Presidential Commission for the Study of Bioethical Issues.

One thing is almost certain: if the $\mathrm{NIH}$ and scientists do not engage with the ethical and animal-welfare issues that are so clearly at the forefront of the public mind, Congress will do it for them, and the result may well be to shut down virtually all research using great apes, as happened in the European Union in 2010.

The committee plans to gather public input at a meeting in Washington DC in August, on a date yet to be announced. $\rightarrow$ NATURE,COM To comment online, click on Editorials at: go.nature.com/xhunqu Researchers would do well to make their views known to the IOM committee, which will receive and consider all public comment at go.nature. com $/ 5$ tdgkt. 